\title{
TYPE SPECIFIC MENINGOCOCCIC AGGLUTININS: II-THE RELATIONSHIP OF TITERS TO THE COURSE OF THE DISEASE ${ }^{1}$
}

\author{
By CAROLYN R. FALK AND EMANUEL APPELBAUM \\ (From the Bureau of Laboratories of the Department of Health of the City of New York)
}

(Received for publication May 19, 1945)

In the first paper of this series (1) a technic was described which affords a simple method of detecting type specific agglutinins in individuals suffering from meningococcic infection. Agglutinin titers over $1 / 100$ were regarded as significant of the presence of specific antibody, while those up to and including $1 / 100$ were considered within the normal range. If this test was to have practical application for diagnostic purposes, or for determining the type of the infecting organism in cases where meningococci were not cultured, it seemed essential to study the agglutinin titers in bacteriologically proved cases of meningococcic infection during the entire course of the disease to determine: (a) When are agglutinins found in diagnostically significant titers? (b) What types of agglutinins are found? (c) Do these correspond in prevalence with the type distribution of recently isolated strains? (d) Do the types of agglutinins in patients' serums correspond in type and valence with the infecting organism in cases where both the infecting organism and the patient's serum were available for study?

The meningococcic agglutinin content of 252 bacteriologically proved cases of meningococcic infection was studied from March, 1942 to March, 1945. Samples of serum were obtained from the same patient from 1 to 34 times at intervals of from 1 to 21 days, i.e., during the acute, subacute, and convalescent phases of the disease. All the patients included in this study received one of the sulfonamide drugs and none received serum.

\section{METHOD}

The method used was that described in our previous paper (1). Briefly, all serums were tested for Group I, Group II and Group II-alpha agglutinins. The cultures used for the antigens were standard stock strain cultures of well-established specificity and antigenicity. Serum dilutions ranged from $1 / 50$ to $1 / 1600$. Each dilution was

1 Presented at the New York Academy of Medicine Clinical Research Meeting, May 16, 1945. increased twofold. The tests were incubated at $37^{\circ} \mathrm{C}$. for 2 hours, centrifuged at high speed for 10 minutes and kept in the refrigerator overnight. Readings were made after centrifugation and also following overnight storage. The last tube showing definite (2 plus) clumping was considered indicative of the titer of the serum.

\section{RESULTS}

Agglutinins in significant titers were found, for 1 or more of the types of meningococci, in 188 of 252 (75 per cent) cases. Only 1 sample of blood was obtained in each of 149 cases, 2 samples were collected in each of 59 instances, and from 3 to 34 samples were taken from each of 47 patients. For purposes of analysis, the 506 samples of serum obtained from these patients were arbitrarily grouped according to the phase of illness during which they were obtained. All samples of serum collected from the first to the fifth day after the onset of the disease were considered as representative of the acute stage, those from the sixth to the tenth day as subacute stage, and those from the eleventh

TABLE I

Distribution of the titers of the same patients tested during the acute, subacute, and convalescent stages of their illness

\begin{tabular}{|c|c|c|c|}
\hline \multirow{2}{*}{$\underset{\text { titer }}{\text { Agk* }}$} & \multicolumn{3}{|c|}{$\begin{array}{l}\text { Stage of illness during which blood } \\
\text { was withdrawn }\end{array}$} \\
\hline & Acute & Subacute & Convalescent \\
\hline Less than $1 / 100$ & $\begin{array}{l}1 \text { to } 5 \text { days } \\
16\end{array}$ & $\begin{array}{l}6 \text { to } 10 \text { days } \\
1^{*}\end{array}$ & $\begin{array}{c}11 \text { to } 90 \text { days } \\
1 * *\end{array}$ \\
\hline $\begin{array}{l}1 / 100 \text { to } 1 / 200 \\
1 / 200 \text { to } 1 / 400 \\
1 / 400 \text { to } 1 / 800 \\
1 / 800 \text { to } 1 / 1600 \\
1 / 1600 \text { and over }\end{array}$ & $\left.\begin{array}{l}0 \\
2 \\
2 \\
3 \\
1\end{array}\right\}$ & $\left.\begin{array}{l}0 \\
5 \\
8 \\
6 \\
4\end{array}\right\} 23$ & $\left.\begin{array}{r}1 \\
2 \\
4 \\
12 \\
4\end{array}\right\} 23$ \\
\hline Total & 24 & 24 & 24 \\
\hline
\end{tabular}

* Serum from this patient showed a titer of $1 / 256$ during convalescent stage.

** Serum from this patient showed a titer of $1 / 1600$ during the subacute stage.

*** 13 patients tested using dilution range of $1 / 64$ to $1 / 1024,11$ patients tested using dilution range of $1 / 50$ to $1 / 1600$ (1). 
TABLE II

Protocols of individual cases of proved meningococcic infection

\begin{tabular}{|c|c|c|c|c|c|c|c|c|}
\hline \multirow{2}{*}{$\begin{array}{c}\text { Case } \\
\text { num- } \\
\text { ber }\end{array}$} & \multirow{2}{*}{ Diagnosis } & \multirow{2}{*}{ Smear } & \multirow{2}{*}{ Culture } & \multirow{2}{*}{ Onset } & \multirow{2}{*}{ Day after onset } & \multicolumn{3}{|c|}{ Agglutination titer } \\
\hline & & & & & & Group I & Group II-a & Group II \\
\hline $1-$ & Meningococcic meningitis & Positive & No growth & $5 / 26 / 43$ & $\begin{array}{l}1,2 \\
3 \\
6 \\
7 \\
8,9 \\
10,12\end{array}$ & $\begin{array}{lr}1 / & 64 \\
1 / & 128 \\
1 / & 256 \\
1 / & 512 \\
1 / 1024 \\
1 / 1024+\end{array}$ & $\begin{array}{l}0 \\
0 \\
0 \\
0 \\
0 \\
0\end{array}$ & $\begin{array}{l}0 \\
0 \\
0 \\
0 \\
0 \\
0\end{array}$ \\
\hline 2- & Meningococcic meningitis & Positive & $\begin{array}{l}\text { Positive } \\
\text { I-II-a }\end{array}$ & $9 / 26 / 43$ & $\begin{array}{l}2 \\
8,10 \\
12 \\
13 \\
17 \\
24 \\
27 \\
33\end{array}$ & $\begin{array}{c}0 \\
1 / 800 \\
1 / 1600 \\
1 / 1600 \\
1 / 1600 \\
1 / 1600 \\
1 / 1600 \\
1 / 200\end{array}$ & $\begin{array}{c}0 \\
0 \\
0 \\
1 / 100 \\
1 / 400 \\
1 / 200 \\
0 \\
0\end{array}$ & $\begin{array}{l}0 \\
0 \\
0 \\
0 \\
0 \\
0 \\
0 \\
0\end{array}$ \\
\hline $3-$ & Meningococcic meningitis & Positive & No growth & $5 / 15 / 43$ & $\begin{array}{l}4 \\
5 \\
6 \\
7 \\
8 \text { to } 15 \\
18 \\
19,20 \\
21 \text { to } 28 \\
30,32 \\
33 \\
34 \text { to } 37,40,42,54 \\
59 \\
66\end{array}$ & $\begin{array}{lr}1 / & 32 \\
1 / & 64 \\
1 / & 128 \\
1 / & 256 \\
1 / & 512 \\
1 / & 256 \\
1 / 1024 \\
1 / & 512 \\
1 / & 256 \\
1 / & 512 \\
1 / & 256 \\
1 / & 128 \\
1 / & 32\end{array}$ & $\begin{array}{l}0 \\
0 \\
0 \\
0 \\
0 \\
0 \\
0 \\
0 \\
0 \\
0 \\
0 \\
0 \\
0\end{array}$ & $\begin{array}{l}0 \\
0 \\
0 \\
0 \\
0 \\
0 \\
0 \\
0 \\
0 \\
0 \\
0 \\
0 \\
0\end{array}$ \\
\hline 4- & $\begin{array}{l}\text { Influenzal meningitis } \\
\text { (control) }\end{array}$ & Positive & $\begin{array}{l}\text { Positive } \\
\text { Type B }\end{array}$ & $11 / 6 / 43$ & $5,11,16$ & 0 & 0 & $\mathbf{0}$ \\
\hline 5- & $\begin{array}{l}\text { Pneumococcic meningitis } \\
\text { (control) }\end{array}$ & Positive & $\begin{array}{l}\text { Positive } \\
\text { Type } 27\end{array}$ & $11 / 8 / 43$ & $7,12,16$ & 0 & 0 & 0 \\
\hline
\end{tabular}

to the ninetieth day as convalescent stage. In 155 instances where more than 1 sample of serum was obtained during a given period, an arithmetic average of the reciprocals of the titers was used, and the 2 or more specimens were considered as a unit. Only 68 of the 149 (46 per cent) serums collected during the acute stage were positive, while 84 of 106 (79 per cent) serums collected during the subacute stage were positive, and 49 of 72 (68 per cent) serums collected during the convalescent phase were positive. The time of onset was unknown in 24 instances. In this group, 18 (75 per cent) serums showed agglutinins in significant titers.

To clarify this problem further, a group of 24 patients was tested 1 or more times successively during each of the acute, subacute and convalescent phases. In instances where more than 1 sample of serum was tested during any one of these periods, the titers were averaged using the method previously mentioned. The distribution of the agglutinin titers of these cases is given in Table I. Sixteen of the 24 cases showed negative agglutination titers during the acute stage. Only 1 case remained negative during the subacute stage but became positive during the convalescent stage. Another case that was positive during the subacute phase became negative during the convalescent phase. The increase in the number of patients showing agglutinins in titers above $1 / 400$ was also marked during the subacute and convalescent phases. In fact, while only 6 cases showed agglutinins over $1 / 400$ during the acute phase, this number was increased to 18 during the subacute and to 20 during the convalescent stage.

Table I shows the general trend of the group as a whole. The variation which was encountered in individual cases can best be shown by the pro- 


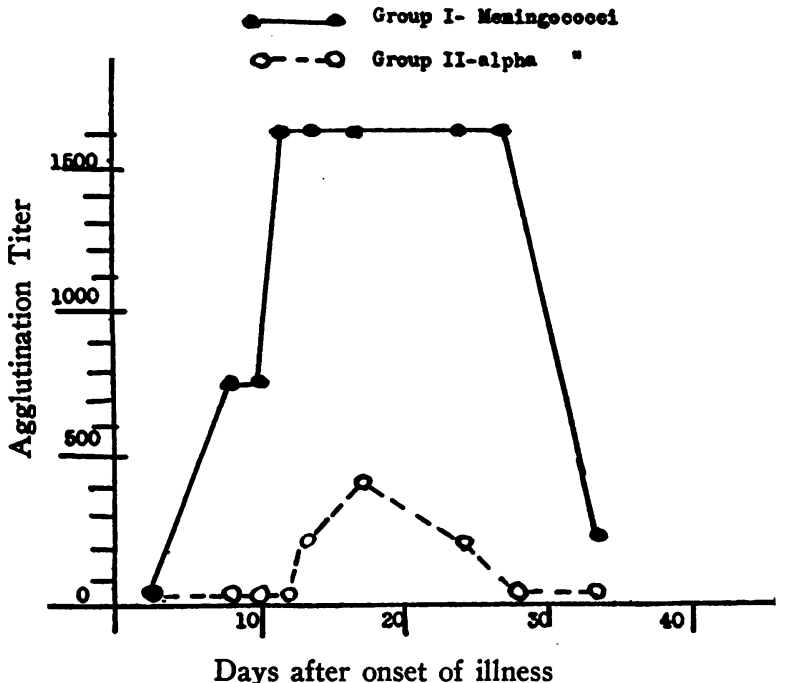

Fig. 1. Agglutination Titers for Group I AND Group II-Alpha Meningococci on Serums Obtained From Patient C. C.

Onset of illness 9/26/43.

tocols of typical cases. Three such cases and 2 control cases are presented in Table II. Case number 1 showed a gradual rise in agglutinin titer during the first 12 days of illness. In case number 2 agglutinins for Group I meningococci persisted until the thirty-third day. In this same instance, agglutinins for Group II-alpha meningococci made a delayed appearance and were observed from the thirteenth to the twenty-fourth day. Finally, in case number 3, samples of serum were taken at almost daily intervals during the entire course of the disease. This case showed a gradual rise in titer during the first 3 weeks, and a gradual decrease in titer from the fifth to the eighth week. The final sample of serum taken 9 weeks after the onset of illness was negative. Case numbers 4 and 5 were representative of a group of 78 control patients, suffering from other forms of meningitis not caused by the meningococcus. Serums collected from these patients at comparable periods to the meningococcic infection cases were negative.

It is of interest to note that essentially the same rise and fall of agglutinin titers was observed in another group of serums collected from 128 clinically typical cases of meningococcic infection, without bacteriological confirmation of the causative agent. This will be the subject of a future report.

These results indicate that the curve of agglutinin production in cases of meningococcic infection was similar to the classical one of other febrile diseases such as typhoid fever (2). Typical curves of agglutinin titers in instances where tests were made on samples collected during the various phases of the diseases are presented in Figures 1 and 2 .

In certain instances, the significance of the test was obscured by the fact that the beginning of the infection probably. preceded the onset of clinical symptoms by a sufficiently long interval to allow for the formation of agglutinins in significant titers. Case numbers 1 and 2 in Table III represent 17 such instances in a group of 47 cases where 3 or more samples of serum were studied. Unfortunately, serums were not obtained in these 17 instances late in convalescence to determine a

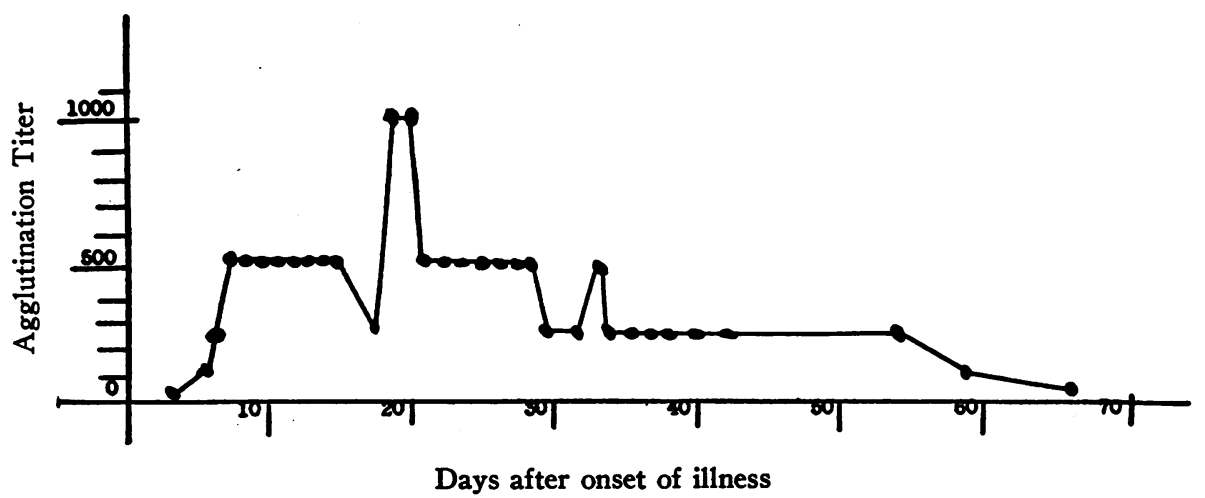

Fig. 2. Agglutination Titers for Group I Meningococci on Serums Obtained from Patient C. C.

Onset of illness $9 / 15 / 43$. 
TABLE III

Protocols of individual cases of proved meningococcic infection showing significant agglutinin titers for type specific meningococci on the day of onset of the disease

\begin{tabular}{|c|c|c|c|c|c|c|c|c|}
\hline \multirow{2}{*}{$\begin{array}{c}\text { Case } \\
\text { number }\end{array}$} & \multirow{2}{*}{ Diagnosis } & \multirow{2}{*}{ Smear } & \multirow{2}{*}{ Culture } & \multirow{2}{*}{ Onset } & \multirow{2}{*}{$\begin{array}{c}\text { Day after } \\
\text { onset }\end{array}$} & \multicolumn{3}{|c|}{ Agglutination titer } \\
\hline & & & & & & Group I & Group II-a & Group II \\
\hline $1^{*}$ & $\begin{array}{l}\text { Meningococcic meningitis with } \\
\text { meningococcemia }\end{array}$ & Positive & $\begin{array}{l}\text { Positive } \\
\text { I-II-a }\end{array}$ & $6 / 18 / 43$ & $\begin{array}{r}1 \\
3 \\
6 \\
15\end{array}$ & $\begin{array}{l}1 / 1024 \\
1 / 512 \\
1 / 1024 \\
1 / 1024\end{array}$ & $\begin{array}{l}1 / 512 \\
1 / 1024 \\
1 / 1024 \\
1 / 256\end{array}$ & $\begin{array}{l}0 \\
0 \\
0 \\
0\end{array}$ \\
\hline $2 \dagger$ & Meningococcic meningitis & Positive & $\begin{array}{c}\text { No } \\
\text { growth }\end{array}$ & $5 / 23 / 43$ & $\begin{array}{r}1 \\
4 \\
8 \\
14 \\
16 \\
19\end{array}$ & $\begin{array}{lr}1 / & 256 \\
1 / & 32 \\
1 / & 64 \\
1 / & 128 \\
1 / & 32 \\
1 / & 512\end{array}$ & $\begin{array}{c}0 \\
0 \\
0 \\
0 \\
1 / 256\end{array}$ & $\begin{array}{l}0 \\
0 \\
0 \\
0 \\
0 \\
0\end{array}$ \\
\hline
\end{tabular}

* 13 instances in a group of 47 cases showed similar high titers on the day of onset.

t 4 instances in a group of 47 cases showed high titers on the day of onset, accompanied by fluctuating titers on the several samples tested.

change in titer. Case number 2 was also typical of a group of 4 instances which showed a fluctuation of agglutinin titers during the first 3 weeks of illness.

Our own studies, as well as those of other observers ( 3 to 9 ), showed that Group I meningococci were the predominating type during the period of this investigation. Since March, 1942, we have classified 347 gram negative diplococci, isolated by this laboratory from samples of spinal fluid or blood. They were typed by the tube agglutination method, using type specific monovalent rabbit antiserums. The typing serums were prepared from the same strains that have been used as antigens in testing the agglutinin content of the patient's serums, and did not show cross reactivity between the different groups of meningococci when tested with strains of known antigenicity. Two hundred and ninety-five (85 per cent) were typed as Group I ; 43 (12.5 per cent) as Group I-II-alpha; 1 (0.3 per cent) as Group II ; 4 (1.2 per cent) as Group II-alpha; and 3 ( 0.9 per cent) could not be classified serologically, although on the basis of fermentation reactions, they belonged to the $N$. meningitidis group.

The type distribution of the agglutinins found in the patients' serums was very similar to the type distribution of the recently-isolated strains.

TABLE IV

Type distribution of meningococcic agglutinins in bacteriologically proved cases of meningococcic infection

\begin{tabular}{|c|c|c|c|c|c|c|c|c|c|c|}
\hline \multirow{3}{*}{$\begin{array}{l}\text { Agglutinins in titers above } \\
1 / 100 \text { for group }\end{array}$} & \multicolumn{8}{|c|}{ Stage of infection during which blood was withdrawn } & \multirow{2}{*}{\multicolumn{2}{|c|}{ Total }} \\
\hline & \multicolumn{2}{|c|}{ Acute } & \multicolumn{2}{|c|}{ Subacute } & \multicolumn{2}{|c|}{ Convalescent } & \multicolumn{2}{|c|}{$\begin{array}{l}\text { Onset } \\
\text { unknown }\end{array}$} & & \\
\hline & Number & Per cent & Number & Per cent & Number & Per cent & Number & Per cent & Number & Per cent \\
\hline$M$ & \multicolumn{2}{|c|}{1 to 5 days } & \multicolumn{2}{|c|}{6 to 10 days } & \multicolumn{2}{|c|}{11 to 90 days } & \multirow[b]{2}{*}{$\begin{array}{r}15 \\
1 \\
0 \\
0 \\
5 \\
0\end{array}$} & \multirow[b]{2}{*}{$\begin{array}{c}66.7 \\
5.5 \\
0 \\
0 \\
27.8 \\
0\end{array}$} & \multirow[b]{2}{*}{$\begin{array}{r}142 \\
2 \\
0 \\
2 \\
36 \\
6 \\
\end{array}$} & \multirow[b]{2}{*}{$\begin{array}{c}75.6 \\
1.1 \\
0 \\
1.1 \\
19.0 \\
3.3\end{array}$} \\
\hline $\begin{array}{l}\text { I } \\
\text { II } \\
\text { II-alpha } \\
\text { Polyvalent serums } \\
\text { I and II } \\
\text { I and II-alpha } \\
\text { I, II, and II-alpha }\end{array}$ & $\begin{array}{r}52 \\
0 \\
0 \\
1 \\
17 \\
2\end{array}$ & $\begin{array}{c}72.2 \\
0 \\
0 \\
1.4 \\
23.6 \\
2.8\end{array}$ & $\begin{array}{r}49 \\
0 \\
0 \\
1 \\
8 \\
2\end{array}$ & $\begin{array}{c}87.7 \\
0 \\
0 \\
1.7 \\
13.3 \\
3.3\end{array}$ & $\begin{array}{r}29 \\
1 \\
0 \\
0 \\
6 \\
2\end{array}$ & $\begin{array}{c}76.3 \\
2.7 \\
0 \\
0 \\
15.7 \\
5.3\end{array}$ & & & & \\
\hline Total & 72 & 100.0 & 60 & 100.0 & 38 & 100.0 & 18 & 100.0 & 188 & 100.0 \\
\hline $\begin{array}{l}\text { Total Group I alone or in com- } \\
\text { bination with other groups }\end{array}$ & 72 & 100.0 & 60 & 100.0 & 37 & 97.3 & 17 & 94.5 & 186 & 98.9 \\
\hline
\end{tabular}


These results are presented in Table IV. One hundred and forty-two of the 188 cases showing agglutinins in significant titers, produced agglutinins for Group I meningococci alone. Two cases showed agglutinins for Group II alone. The remaining 44 cases showed serums with a broader valence. Agglutinins for Group II-alpha, as well as for Group I, were observed in 36 instances; agglutinins for Group I and Group II in 2 cases ; and agglutinins for Group I, Group II and Group II-alpha in 6 instances. The valence of the serum did not appear to have any relation to the phase of the disease during which the serum was collected. Serums with a broad valence were found in 20 of 72 ( 28 per cent) cases during the acute phase; in 11 of 60 (17 per cent) cases during the subacute phase; and in 8 of 38 (18 per cent) cases tested during the convalescent phase. They were also found in 5 of 18 (28 per cent) cases in which the date of onset was unknown. Furthermore, in 10 of 21 instances, in which successive samples of serum from the same patient were tested, Group II-alpha agglutinins were not evident in the first sample of serum tested, but were present in subsequent ones taken either late in the first week or during the second week of illness. The protocols of case number 2 in Table II and number 2 in Table III are typical of such findings.

The infecting organisms were available for classification in 82 of the 252 cases included in this study. Agglutinins in significant titers were observed in 59 of these patients, while the remaining 23 yielded negative results. Twenty of the 23 patients whose serums failed to show agglutinins were tested only once. These included 12 patients tested during the acute stage, 3 tested during the subacute stage, 1 tested during the convalescent stage, and 4 instances with time of onset unknown. Three cases were tested during the acute and subacute phases, but not during the convalescent phase. Table V shows that 37 of the 44 strains which reacted with only 1 type of monovalent rabbit antiserum elicited only 1 type of agglutinins in the patient's serum, while 7 strains produced a serum with a broader valence. On the other hand, 12 of 15 organisms which reacted with 2 or more types of monovalent rabbit antiserum evoked agglutinins for more than 1 type of meningococci. No organisms in this series. were typed as either Group II or Group II-alpha alone. These results indicate that there is a correlation between the infecting organism and the antibodies produced in the patient's serum.

\section{DISCUSSION}

The significance of finding type specific meningococcic agglutinins in human serums in the past was obscured by the antibodies introduced, in the majority of cases, when therapeutic antiserum was used. The use of chemotherapy alone, however, has made it possible to study the antibodies produced by the infecting organism itself.

The results of this study show that the type specific agglutinin production in cases of bacteriologically proved meningococcic infection followed the classical curve of other febrile diseases. The titers varied from $1 / 200$ to $1 / 1600$. Agglutinins were observed more regularly during the subacute than during the acute phase and reached their maximum titers during the early part of the convaies-

TABLE $v$

Comparison of the group of the infecting organism with the group of the agglutinins found in the patient's serum

\begin{tabular}{|c|c|c|c|c|c|c|c|c|c|}
\hline \multirow{2}{*}{$\begin{array}{l}\text { Infecting organism } \\
\text { classified as group }\end{array}$} & \multirow{2}{*}{$\begin{array}{c}\text { Total } \\
\text { number } \\
\text { of } \\
\text { cases }\end{array}$} & \multirow{2}{*}{\multicolumn{2}{|c|}{$\begin{array}{l}\text { Total number } \\
\text { agglutination titer }\end{array}$}} & \multicolumn{6}{|c|}{ Group agglutinins found in patient's serum } \\
\hline & & & & $\mathbf{I}$ & II & UI-alpha & I and & I and & I, II, and \\
\hline $\begin{array}{l}\text { I } \\
\text { II } \\
\text { II-alpha } \\
\text { I and II } \\
\text { I and II-alpha } \\
\text { I, II, and II-alpha }\end{array}$ & $\begin{array}{r}65 \\
0 \\
0 \\
0 \\
16 \\
1\end{array}$ & $\begin{array}{c}1 / 100 \text { or } \\
\text { less } \\
21 \\
0 \\
0 \\
0 \\
2 \\
0\end{array}$ & $\begin{array}{c}a b o v e \\
1 / 100 \\
44 \\
0 \\
0 \\
0 \\
14 \\
1\end{array}$ & $\begin{array}{r}37 \\
0 \\
0 \\
0 \\
2 \\
1\end{array}$ & $\begin{array}{l}\mathbf{0} \\
\mathbf{0} \\
\mathbf{0} \\
\mathbf{0} \\
\mathbf{0} \\
\mathbf{0}\end{array}$ & $\begin{array}{l}0 \\
0 \\
0 \\
0 \\
0 \\
0\end{array}$ & $\begin{array}{l}\mathbf{1} \\
\mathbf{0} \\
\mathbf{0} \\
\mathbf{0} \\
\mathbf{0} \\
\mathbf{0}\end{array}$ & $\begin{array}{r}5 \\
0 \\
0 \\
0 \\
10 \\
0\end{array}$ & $\begin{array}{l}1 \\
0 \\
0 \\
0 \\
2 \\
0\end{array}$ \\
\hline Total & 82 & 23 & 59 & 40 & 0 & $\mathbf{0}$ & 1 & 15 & 3 \\
\hline
\end{tabular}


cent phase. There was, however, considerable variation in individual cases, both as to the time at which the agglutinins were first observed and their persistence in the patient's serum. These observations demonstrate the importance of testing successive specimens from the same patient, especially during the first 2 or 3 weeks of illness. As recovery progressed, there was a gradual decrease in the agglutinin titer to pre-infection levels.

Agglutinins for Group I, Group II and Group II-alpha were found alone and in combination. Agglutinins for Group I organisms, which were the prevalent type in the outbreak studied were found in 99 per cent of the serums. There was also correlation between the infecting organism and its homologous human serum in cases where both the infecting organism and the serum were available for study. This indicated the validity of using the agglutination test, in titers above $1 / 100$, as a means of determining the type of the infecting organism in cases where meningococci were not cultured from the spinal fluid or blood and in which the "quellung" test was unsuccessful. The test may also be useful as an additional diagnostic procedure in cases of suspected meningococcic infection where other laboratory confirmation is lacking. In this connection, the importance of performing several tests to demonstrate the development of the change of agglutinin titers cannot be overemphasized.

An exact explanation for finding polyvalent human serums cannot be given on the basis of the facts on hand. Since all the usual tests have been applied to insure the specificity and antigenicity of the strains used as test antigens, it would not appear that these cross reactions are due to unsuitable and nonspecific antigens. There is a suggestion that it may be due to the valence of the infecting organism or to the remote possibility of 2 separate infections by 2 different groups of meningococci.

It has been apparent that the meningococci isolated during the period of this investigation had a high degree of antigenicity. This has probably been one of the factors in the demonstration of type specific agglutinins. Variation in antigenicity, as well as the different technics employed, may account for the confusing results obtained by different investigators in the past.
A group of workers (10) recently reported essentially similar results in a group of 47 bacteriologically proved cases of meningococcic infection, although they obtained a lower range of agglutinin titers. It should be noted that these investigators used freshly-isolated strains and a slightly different technic for their agglutination test. In our original paper (1), we compared several methods of incubation, which included a centrifugation method similar to the one employed by Dowling and his collaborators. We pointed out in that report that immediate centrifugation did not appreciably alter the titer of the serum.

The usefulness and the limitations of this test as a diagnostic procedure are those of all other serologic tests. In the absence of clinical evidence, it is not possible to distinguish between active and latent infection. We showed (1) that agglutinins in significant titers were found in healthy hospital and laboratory personnel in repeated contact with the infection. In these instances, no attempt was made to correlate these findings with the carrier state. However, in 1935, one worker (11) was able to demonstrate agglutinins in the serums of carriers and felt that this condition could be looked on as an infection. In this connection we should like to mention also the finding of an apparent source of false positives in a group of 11 of 46 instances of gonococcic infection. The significance of this observation merits further study.

\section{SUMMARY AND CONCLUSIONS}

1. Agglutinins were found in diagnostically significant titers in the serums of bacteriologically proved cases of meningococcic infection during the acute, subacute, and convalescent phases.

2. There was considerable variation in individual cases both as to the time at which the agglutinins first appeared in significant titers and their persistence in the patient's serum. Titers fell to pre-infection levels between the third week and fourth month after onset.

3. Agglutinins were found for Group I, Group II, and Group II-alpha meningococci alone and in combination with each other.

4. The agglutinins corresponded in prevalence with the type distribution of the infecting organisms. 
5. The type of the agglutinins found in the patients' serums corresponded with its homologous infecting organism in all cases where both the organism and the serum were available for study.

6. The agglutination test may be useful in titers above $1 / 100$ in determining the type of the infecting organism in cases where meningococci are not cultured from the blood or spinal fluid and in which the "quellung" test is unsuccessful.

7. Excepting diseases due to the gonococcus, this test may be of value as an additional diagnostic procedure in cases of suspected meningococcic infection where other laboratory confirmation is lacking.

The technical assistance of Miss Diana Blitz in the execution of this work is acknowledged with thanks. We are also indebted to Miss Ruth Gosling, Miss Helen Ackermann, and Miss Marie Romano for cooperation in obtaining the specimens of blood and for the isolation of the meningococcus cultures.

\section{BIBLIOGRAPHY}

1. Falk, C. R., and Appelbaum, E., Type specific meningococcic agglutinins in human serums: I-Description of Method. Proc. Soc. Exper. Biol. and Med., 1944, 57, 341.
2. Jorgenson, A., Schwankungen des agglutinations vermogens des blutes im verlaufe des typhus abdominalis. Zentralbl. f. Bakt., 1905, 38, 556.

3. Cohen, S. M., Studies on meningococcus strains. Annual report of the Division of Laboratories and Research, N. Y. State Department of Health, 1942, p. $32 ; 1943$, p. 33.

4. Kuhns, D. M., and Feldman, H. A., Laboratory methods used in determining the value of sulfadiazine as a mass prophylactic against meningococcic infections. Am. J. Pub. Health, 1943, 33, 1461.

5. Mueller, J. H., The relation of the carrier to epidemic meningitis. Ann. Int. Med., June 1943, 18, 974.

6. Thomas, L., and Dingle, J. H., Investigations of meningococcal infection. I. Bacteriological aspects. J. Clin. Invest., 1943, 22, 353.

7. Phair, J. J., Schoenbach, E. B., and Root, C. M., Meningococcal carrier studies. Am. J. Pub. Health, 1944, 34, 148.

8. Pizzi, M., A severe epidemic of meningococcus meningitis in Chile, 1941-1942. Am. J. Pub. Health, 1944, 34, 231.

9. Branham, S. E., Value of typing meningococci. Am. J. Pub. Health, 1945, 35, 233.

10. Dowling, H. F., Mayer, R. L., Sweet, L. K., and Dumoff-Stanley, E., A study of the agglutinin response in patients with meningococcic meningitis. J. Clin. Invest., 1945, 24, 160.

11. Rake, G., Studies on meningococcus infection. VII. The study of an isolated epidemic. J. Exper. Med., 1935, 61, 545. 